\title{
A oficina pedagógica de matemática como atividade
}

\section{The workshop educational mathematics as activity}

\author{
Maria Lucia Panossian ${ }^{1}$ \\ Adnielson Lima da Silva ${ }^{2}$ \\ Fabiana Pallu ${ }^{3}$ \\ Luciana Schreiner de Oliveira ${ }^{4}$
}

\begin{abstract}
RESUMO
Este artigo pretende evidenciar os princípios que regem a organização da Oficina Pedagógica de Matemática como ação de extensão estruturada como atividade, destacando necessidades dos professores, objeto e objetivos das ações, o trabalho colaborativo, a situação desencadeadora de aprendizagem, a Atividade Orientadora de Ensino. Também são apresentados os resultados obtidos a partir do desenvolvimento durante o ano de 2015 das Oficinas Pedagógicas de Matemática como um projeto de extensão oferecido aos professores da rede estadual do Paraná e vinculado ao Departamento Acadêmico de Matemática da UTFPR - Câmpus Curitiba. Destaca-se a importância de ações como esta no ambiente universitário que, sendo estruturadas como atividade, aliam pesquisa e extensão possibilitando a formação continuada de professores.
\end{abstract}

\begin{abstract}
This article at it presents principles of that guide the work with the Pedagogical Workshops Mathematics from the historicalcultural theory and activity theory, highlighting the collaborative work, learning triggering situation, teaching-orienteering activity among others. Are also presented the results obtained from the development during 2015 of Mathematics Pedagogical Workshops as an extension project offered to teachers from the state of Paraná network and linked to the Academic Department of Mathematics UTFPR - Câmpus Curitiba. Highlights the importance of actions like this in the university environment that is structured as activity combine research and extension allowing the continuing education of teachers.
\end{abstract}

Keywords: Activity. Educational workshop. Teacher training. Mathematics education.

Palavras-chave: Atividade. Oficina pedagógica. Formação de professores. Ensino de matemática.

\footnotetext{
${ }_{1}^{1}$ Professora do Departamento Acadêmico de Matemática da Universidade Tecnológica Federal do Paraná - Câmpus Curitiba. Professora do PPGECM (UFPR), e do PPGFCET (UTFPR). Membro do Grupo de Estudos e Pesquisas sobre Atividade Pedagógica (GEPAPe) e do Grupo de Estudos e Pesquisas em Formação de Professores (GeForProf). E-mail: mlpanossian@utfpr.edu.br

2 Professor da rede estadual do Paraná. Mestrando do Programa de Pós-Graduação em Educação em Ciências e Matemática (PPGECM) da Universidade Federal do Paraná (UFPR). E-mail: adnielson@seed.pr.gov.br

${ }^{3}$ Professora da rede estadual do Paraná. Graduada em Matemática. E-mail: fapallu@yahoo.com.br

${ }^{4}$ Professora do Departamento Acadêmico de Matemática da Universidade Tecnológica Federal do Paraná - Câmpus Curitiba. Membro do Grupo de Estudos e Pesquisas em Formação de Professores (GeForProf). E-mail: lucianaoliveira@utfpr.edu.br
} 


\section{Introdução}

A necessidade de formação continuada de professores tem sido destacada tanto pela fragilidade da formação inicial, quanto pelo desenvolvimento profissional dos professores como indica relatório da Fundação Carlos Chagas (DAVIS; NUNES; ALMEIDA, 2011) que verifica como este processo de formação tem acontecido em secretarias estaduais e municipais de Educação de todo Brasil. Embora destaquem-se programas como Pró-Letramento e Gestar oferecidos pelo Governo Federal que oferecem tutoria aos professores e material para os estudantes, o relatório indica que

Por outro lado, cabe lembrar que esses programas, justamente em razão de apresentarem tais características, pouco favorecem a necessária autonomia dos professores para diagnosticar a situação de aprendizagem dos alunos, planejar suas aulas em conformidade com o obtido, implementar e avaliar seu plano de trabalho, condições imprescindíveis para que se possa assumir a autoria da docência. (DAVIS; NUNES; ALMEIDA, 2011, p.98-99).

O referido relatório também retrata que boa parte das secretarias estaduais e municipais que foram pesquisadas oferecem formação aos professores na forma de cursos de curta e longa duração, palestras e oficinas, mas não garante estabelecimento de vínculos estre a formação do professor e as condições em seu ambiente de trabalho, não desenvolvendo uma cultura de aproximação e interação entre os diferentes sujeitos da escola. Nessa perspectiva, destacam o sucesso de práticas colaborativas que envolvem a formação dos professores articulada à equipe gestora das escolas e que "Independentemente da abordagem seguida na Formação Continuada dos docentes, grande parte das SEs investigadas declara considerar mais produtivas as modalidades de Formação Continuada que perduram no tempo e que ocorrem de maneira sistemática" (DAVIS; NUNES; ALMEIDA, 2011, p.100)

Além disso "Ficou claro que as SEs não avaliam os professores após sua participação em atividades de formação continuada" (Davis, Nunes, Almeida, 2011, p.102) e não acompanham os professores em formação. 
O relatório indica, ainda, proposições para a formação continuada dos professores, que envolvem: investimento na formação inicial para que a formação continuada não tenha caráter compensatório; estabelecimento de políticas públicas que formem colaborativamente professores e equipe gestora; ampliação da atuação da formação continuada e, entre outros, o vínculo com a universidade considerando que "Explorar adequadamente o papel das universidades na formação continuada, elaborando propostas que favoreçam sua interação com as comunidades escolares, algo essencial para que tomem conhecimento de suas necessidades e demandas". (DAVIS; NUNES; ALMEIDA, 2011, p.105)

No que diz respeito à universidade, normalmente uma das possibilidades de interação com as escolas de Educação Básica efetua-se no oferecimento de formação continuada para os professores por meio das ações de extensão. E é como ação de extensão que são constituídas as Oficinas Pedagógicas de Matemática (OPM) na Universidade Tecnológica Federal do Paraná - Campus Curitiba.

Mas frente a estas necessidades e condições de formação continuada dos professores, qual o significado de organizar e realizar mais um curso de extensão ainda que com outro formato mas similar aos oferecidos pela rede e com alcance limitado para a formação de professores tendo como princípio a teoria históricocultural?

Para trazer elementos em resposta a esta questão, pretende-se nesse texto evidenciar os princípios que regem a organização da Oficina Pedagógica de Matemática como ação de extensão estruturada como atividade, destacando necessidades dos professores, objeto e objetivos das ações. Identificada como um modo de formação continuada a OPM possibilita o vínculo entre o processo de formação dos professores e seu local de trabalho.

Considera-se ainda que a formação de professores contempla a apropriação de conceitos historicamente acumulados e o modo de ensino, sendo necessariamente contínua e vinculada à atuação prática do professor. 


\section{A estruturação das OPMs como atividade}

O trabalho com a OPM vinculado à teoria histórico-cultural não é novo. Um resgate breve desse modo de formação nos conduz ao trabalho de Moura (1996). Originalmente, em sua tese de doutorado Moura (1992) pesquisou a construção do signo numérico em situações de ensino realizando a pesquisa junto a professores de uma escola da rede municipal de São Paulo. Posteriormente, convidado para assessorar o sistema municipal de São Paulo (na década de 90) adotou como modo de formação dos profissionais o processo de desencadear a atividade dos sujeitos participantes, no caso coordenadores pedagógicos e professores escolhidos para representar o seu Núcleo de Ação Educativa (NAE) por região. Neste modelo nasce a OPM, vinculadas à Faculdade de Educação da Universidade de São Paulo e composta por pesquisadores e professores da rede municipal. As situações de ensino desenvolvidas na OPM foram sistematizadas em ações coletivas e constituíram uma proposta de matemática para a Educação Infantil.

Encontramos também Oficinas Pedagógicas de Matemática sendo realizadas na Universidade Estadual de Maringá. A OPM/UEM é composta por professores da educação infantil e dos anos iniciais do Ensino Fundamental e egressos do curso de pedagogia.

A apropriação do conhecimento teórico pelos professores que ensinam matemática e a sua forma de ensiná-lo aos escolares são características essenciais da OPM/UEM, a qual é concebida como espaço de aprendizagem docente tanto para os participantes quanto para os professores-formadores. (MORAES; ARRAIS; GOMES; GRACILIANO; VIGNOTO, 2012, p.138)

Destaca-se que a OPM, entendida como espaço de formação de professores, se caracteriza como espaço de aprendizagem considerado como "lugar de realização da aprendizagem dos sujeitos orientado pela ação intencional de quem ensina" (CEDRO, 2004, p,47) e também espaço para pesquisa, considerando que por meio dela pode-se investigar a formação docente. 
No caso da OPM/UEM, o foco dos encontros são “...o estudo de referenciais teórico-metodológicos, elaboração, desenvolvimento e análise de atividades de ensino" (MORAES et al., 2012, p.142).

Também se desenvolvem Oficinas Pedagógicas de Matemática em Ribeirão Preto, com a intenção de desencadear o processo formativo de professores da educação infantil e das séries iniciais do ensino fundamental, pautado nos pressupostos da Atividade Orientadora de Ensino. Na OPM/RP são apresentadas situações problemas que permitam a apropriação de conhecimentos matemáticos, mas também a conscientização das ações da própria prática docente. Nesse movimento é possível reconhecer os aspectos que caracterizam o conhecimento matemático como produto cultural e como se dá a organização de seu ensino no sistema escolar, principalmente na Educação Infantil e no Ensino Fundamental.

A pesquisa de Moretti e Moura (2011) que tinha como objetivo investigar o processo de formação de professores em atividade de ensino, ao elaborarem coletivamente situações desencadeadoras de aprendizagem, teve como espaço de pesquisa um curso de extensão, que foi desenvolvido na perspectiva das Oficinas Pedagógicas de Matemática e assim sendo previa momentos de ação coletiva dos professores pela necessidade de organização de propostas de ensino que posteriormente foram desenvolvidas com os estudantes e reelaboradas pelo grupo de professores após análise. Os autores ressaltam que

O processo de reflexão, avaliação e reorganização das próprias ações no decorrer do próprio trabalho reforçou o aspecto orientador do plano de ações. Pudemos perceber, na análise dos dados, que, à medida que os professores foram constituindo-se como autores das propostas - o que incluiu a definição de objetivos, a escolha ou criação de instrumentos e a organização autônoma de ações -, essa reorganização das ações constituiu-se como etapa necessária do trabalho e decorrente da própria avaliação dos professores. Esse movimento autônomo de criação e recriação das propostas de ensino nos indica a apropriação do professor sobre o próprio objeto de trabalho. (MORETTI; MOURA, 2011, p.446).

Ainda que as condições de organização sejam diferentes em cada uma das instituições, há um princípio que rege esta organização, a estruturação da Oficina Pedagógica de Matemática, como atividade. Considera-se que ao desencadear no 
sujeito uma necessidade (de ensinar) e o colocar em atividade, seu objeto se torna a apropriação de modos e conteúdos de ensino.

A atividade é entendida aqui como unidade de análise do psiquismo humano (LEONTIEV, 1975, 1983, 1994). Para Leontiev, a atividade dos sujeitos possui uma certa estrutura e elementos que se desenvolve dentro de um sistema de relações da sociedade. A atividade não se constitui unicamente a partir de 'reações' do sujeito aos acontecimentos e vínculos sociais considerados 'externos', mas o sujeito se configura como pertencente a esta sociedade e desta forma constitui sua consciência e personalidade.

Considera-se que os professores se formam e desenvolvem envolvidos em atividade de ensino.

O professor que se coloca, assim, em atividade de ensino continua se apropriando de conhecimentos teóricos que lhe permitem organizar ações que possibilitem ao estudante a apropriação de conhecimentos teóricos explicativos da realidade e o desenvolvimento do seu pensamento teórico, ou seja, ações que promovam a atividade de aprendizagem de seus estudantes. (MOURA, 2010, p. 90).

O caráter objetal é uma das principais características constitutivas do que Leontiev compreende por atividade, isto é a atividade está vinculada a um objeto (que é seu motivo real) e o que dirige a atividade a este objeto é a necessidade.

Outro de seus aspectos consiste em que o objeto mesmo da atividade se revela ao sujeito como resposta a uma ou outra de suas necessidades. Desta maneira as necessidades estimulam a atividade e a dirigem por parte do sujeito, mas elas são capazes de realizar estas funções a condição de que sejam objetivas. (LEONTIEV, 1983, p.72).

O objeto pode ser externo ao sujeito ou existir em sua imaginação, ideia. No caso da atividade de ensino consideramos que o objeto é a apropriação de conhecimentos teóricos pelos estudantes, sendo a necessidade de ensinar que dirige o professor a este objeto.

A atividade não pode existir sem um motivo, ou seja, sem o objeto para o qual se dirige. A atividade é concretizada a partir de ações que se dirigem a objetivos conscientes. Ainda que sejam estimuladas pelo motivo, as ações se dirigem a objetivos elaborados conscientemente. Por exemplo, a atividade de 
ensino só pode existir se concretizada a partir do estabelecimento de objetivos conscientes pelo professor que dirigem suas ações que podem ser de planejamento, de elaboração de material didático, de avaliação etc. Assim, ação e atividade não se confundem. Uma ação pode ser parte constituinte de diferentes atividades do sujeito.

O estabelecimento de objetivos conscientes que irão direcionar as ações são dados a partir de condições objetivas. Além de seu aspecto intencional (objetivo que deve atingir) as ações têm também um aspecto operacional dado pelas condições objetivas de execução e concretização. Ações são diferentes de operações, cujo destino a curto ou longo prazo é de transformar-se em função mecânica.

E assim, do fluxo geral da atividade que forma a vida humana em suas manifestações superiores mediadas pelo reflexo psíquico, se desprendem em primeiro termo, distintas - especialmente atividades conforme o motivo que as impele, depois se desprendem as ações - processos - subordinados a objetivos conscientes; e finalmente, as operações que dependem diretamente das condições para atingir o objetivo concreto dado. (LEONTIEV, 1983, p.89).

Estes elementos iniciais sintetizados aqui sobre a estrutura da atividade nos ajudam a argumentar e fundamentar o trabalho nas Oficinas Pedagógicas de Matemática, estruturados a partir do conceito de Atividade.

A formação continuada de professores através da OPM pretende desencadear a necessidade dos participantes de ensinar voltada ao seu objeto/motivo real de potencializar a apropriação de conhecimentos teóricos pelos estudantes. Trata-se de um processo coletivo, a reunião entre professores para conscientemente estabelecer objetivos e ações para concretizar estes objetivos. Neste movimento, na interação entre os participantes, nas conversas sobre as condições de cada uma das escolas em que atuam, os professores reconhecem operações (dadas as condições objetivas) para concretizar seus objetivos por meio das ações. 
Ao atuarem coletivamente, refletem e conscientizam suas ações de ensino, desta forma a reunião coletiva dos professores é uma das condições de formação, bem como trabalho e o vínculo estabelecidos a longo prazo.

De forma mais sistemática o trabalho na OPM é desenvolvido por meio da Atividade Orientadora de Ensino (AOE), conceito também proposto por Moura (1996, 2001, 2010). Os elementos da atividade estão presentes na Atividade Orientadora de Ensino

$\mathrm{Na} \mathrm{AOE}$, ambos, professor e estudante, são sujeitos em atividade e como sujeitos se constituem indivíduos portadores de conhecimentos, valores e afetividade, que estarão presentes no modo como realizarão as ações que têm por objetivo um conhecimento de qualidade nova. Tomar consciência de que sujeitos em atividade são indivíduos é primordial para considerar a AOE como um processo de aproximação constante do objeto: o conhecimento de qualidade nova. A atividade assim, só pode ser orientadora. Nesse sentido, a AOE toma a dimensão de mediação ao se constituir como um modo de realização do ensino e de aprendizagem dos sujeitos que, ao agirem num espaço de aprendizagem, se modificam e, assim, também se constituirão em sujeitos de qualidade nova. (MOURA, 2010, p. 97).

Como já ressaltado, a OPM se caracteriza como um espaço de aprendizagem para os professores, no sentido de desencadear a necessidade e dirigir o processo em busca do seu objeto: apropriação de conhecimento teórico pelos estudantes. Nessa busca pelo objeto os professores organizam e reorganizam seus próprios modos de ensino e se formam neste processo.

Assim, na OPM não há a preocupação em apresentar diferentes situações de ensino aos professores aumentando seu repertório, a intenção não é esgotar uma lista de opções e possibilidades de situações, mas possibilitar que, coletivamente, sejam criadas ou recriadas as situações. Nesse processo coletivo acompanhado também de ação prática desenvolvida com os estudantes, os professores analisam e se conscientizam de seus objetivos e ações. 


\section{O processo de constituição e o desenvolvimento do trabalho na OPM/Curitiba}

O projeto de extensão ‘Oficinas Pedagógicas de Matemática’ foi cadastrado pela primeira vez em Curitiba no ano de 2015 vinculado ao Departamento Acadêmico de Matemática da Universidade Tecnológica Federal do Paraná (UTFPR). O objetivo definido para esta ação de extensão foi o de "Promover entre professores da universidade, professores da rede básica de ensino e estudantes da graduação (licenciatura em matemática) a articulação teoria/prática (práxis) que fundamentem suas ações dentro da atividade de ensino de matemática”. Além do objetivo geral, foram definidos objetivos específicos:

- aprofundar junto a professores da rede pública do Estado do Paraná e alunos da graduação da licenciatura em Matemática da UTFPR o estudo sobre a linha teórica histórico-cultural (VYGOTSKY, 1997) e sua relação com a prática de ensino de matemática.

- gerar coletivamente situações de ensino envolvendo conteúdo matemática baseado nos pressupostos da teoria da atividade e da teoria histórico-cultural.

Iniciada em meados de abril de 2015 , foram oferecidas 20 (vinte) vagas das quais 14 foram preenchidas, sendo 11 professores da rede pública do Paraná, e três estudantes da licenciatura. É importante destacar que a carga horária (anual) do projeto no desenvolvimento com os professores foi estipulada em 120 horas, sendo 60 horas para o primeiro semestre e 60 horas para o segundo semestre, realizadas em encontros semanais de duas horas presenciais e duas horas realizadas a critério do professor para os processos de leitura, escrita, planejamento entre outros.

No cronograma do primeiro semestre foram previstos encontros para discussão de textos teóricos ou de apresentação de situações desencadeadoras de aprendizagem (MOURA, 2010; MOURA; SFORNI; ARAUJO, 2011; SOUSA; PANOSSIAN; CEDRO, 2014) ou que tratassem do processo de Atividade Orientadora de Ensino; encontros para discussão de conteúdos matemáticos específicos a serem definidos com os professores; e encontros dedicados ao 
trabalho coletivo e reunião de subgrupos constituídos entre os participantes da OPM.

Ao longo do semestre por motivos variados, excesso de carga horária, problemas familiares, alterações de horário, entre outros, nove participantes se evadiram. Não forem coletados dados para confirmar, mas pode-se supor que tenha ocorrido falta de compreensão sobre o processo das oficinas. A ideia de oficinas remete a algo ' prático' e é possível que os participantes tivessem a expectativa de encontrar elementos e ações práticas a cada novo encontro, ou mesmo que o processo fosse nos moldes de um curso em que os participantes recebem as informações somente. Também é possível que aguardassem situações 'inovadoras' e/ou 'criativas' que pudessem reproduzir em suas salas de aula. Entretanto o que se entende aqui por OPM estruturada como atividade, remete à construção e trabalho coletivo, sendo que ainda que se defina inicialmente um conteúdo e se apresentem algumas situações, é essencialmente o trabalho coletivo que possibilitará a elaboração e organização de situações desencadeadoras de aprendizagem dos estudantes.

Com os cinco participantes que se mantiveram durante todo o semestre foi definido o conteúdo a ser trabalhado (Razões trigonométricas no triângulo retângulo) e a situação desencadeadora de aprendizagem (a rampa de skate de dedo). Até o final de Junho de 2015 haviam sido planejadas ações e operações vinculadas à esta situação desencadeadora de aprendizagem.

O trabalho da OPM, foi retomado no segundo semestre de 2015 agregandose ainda outros dois participantes. Assim, a OPM continuou com seis professores pois no segundo semestre um dos que estava no primeiro semestre não retornou. Destes seis, quatro faziam parte da mesma escola, o que viabilizou a organização do cronograma do segundo semestre visando o desenvolvimento da situação desencadeadora de aprendizagem planejada no primeiro semestre, junto à esta escola.

Durante o segundo semestre todo o trabalho de organização foi coletivo, desde o cronograma e pauta dos encontros até as análises realizadas sobre a situação desenvolvida. As ações de ensino planejadas foram desenvolvidas na 
escola da rede estadual do Paraná Colégio Estadual Desembargador Guilherme A. Maranhão com os alunos do $1^{\circ}$ Ano do Ensino Médio. Resultados mais detalhados desse desenvolvimento foram apresentados como relato de experiência pelos professores que participaram da OPM no XIII Encontro Nacional de Educação Matemática (SILVA; PALLU; PANOSSIAN; SCHREINER, 2016).

No trabalho com a OPM, alguns indícios podem ser encontrados no sentido de reconhecer que os professores participantes se encontravam em atividade. Um deles é o de que o objeto/motivo real de participação se unificou no grupo e estava voltado para a constituição da situação desencadeadora de aprendizagem que possibilitasse o desenvolvimento do conceito de razões trigonométricas no triângulo retângulo.

Leontiev (1994, p. 70) diferencia os "motivos compreensíveis" dos "motivos eficazes". Enquanto, que "motivos eficazes" coincidem com o objeto da atividade, o mesmo não acontece com os "motivos compreensíveis". O autor, no entanto, afirma que motivos apenas compreensíveis podem vir a se tornar motivos eficazes. Poderiam ser considerados motivos apenas compreensíveis a permanência dos professores na OPM para conseguir um certificado para evolução funcional, entretanto o envolvimento dos professores no processo de estudo e desenvolvimento coletivo da situação desencadeadora de aprendizagem se revelou um motivo eficaz, coincidindo com o objeto da atividade, potencializar a apropriação de conhecimentos teóricos pelos estudantes.

Assim, durante o primeiro semestre, em reuniões semanais de duas horas as discussões se alternaram entre estudos de conceitos da teoria históricocultural; o conceito de Atividade Orientadora de Ensino (AOE); estudo histórico sobre razões trigonométricas no triângulo retângulo e planejamento e organização das ações de ensino.

A apresentação e discussão com os professores de pressupostos da teoria histórico-cultural, da teoria da atividade e da Atividade Orientadora de Ensino, possibilitaram a conscientização do próprio processo de ensino pelos professores, articulando teoria e prática. Em geral os professores estão acostumados a aprender 'pela experiência', ou seja, na vivência de sala de aula, em sua prática 
sistematizam alguns conhecimentos relacionados à organização do ensino e os reproduzem. Por exemplo, encontram modos de agir com turmas grandes, ou com determinado conteúdo estipulado pela grade curricular entre outros. Entretanto, ao realizar leitura e discussões bem como compreender princípios teóricos tem condições de analisar e refletir sobre sua prática. Reconhecem então a organização do ensino como um fenômeno que deve ser conscientemente definido e analisado constantemente. Encontram fundamentos e explicações para suas ações.

Como uma das ações dentro da OPM, os professores foram requisitados a definir o conteúdo a ser estudado coletivamente. Os professores identificaram que as razões trigonométricas no triângulo retângulo são fonte de incompreensão por parte dos estudantes e geralmente apresentada de forma técnica e sem significado. Com a concordância de todos do grupo, o tema foi definido para estudo.

Uma das propostas dentro da Oficina Pedagógica de matemática é que o tema seja estudado em seu movimento histórico e lógico, ou seja, é necessário que haja o entendimento das necessidades que dirigiram a constituição de determinado conceito na experiência humana. É importante destacar que o estudo do movimento histórico e lógico dos conceitos não se confunde com o estudo da história da matemática que sistematiza os fatos conforme tempo e espaço ou causas e consequências do acontecimento. Para compreender o movimento histórico e logico de determinado conceitos é importante recorrer aos elementos investigados e sistematizados pelos historiadores do conhecimento matemático, mas destacando dimensões filosóficas e psicológicas e o movimento do pensamento que conduziu a determinados fatos e acontecimentos. Além disso, esse estudo do movimento histórico e lógico do conceito é fonte de estudo do professor, mas não precisa ser apresentado ao estudante de forma sistematizada ou como estratégia metodológica de ensino, entretanto o seu estudo é elemento de formação do professor para que tenha condições de organizar situações de ensino que revelem a necessidade de determinado conceito aos estudantes. 
É importante considerar que os conceitos científicos, que se pretende que sejam apropriados pelos estudantes, são historicamente determinados, sendo necessário considerar o grau de conhecimento adquirido em determinado momento histórico (VIGOTSKI, 2001). Entretanto, a maioria dos professores participantes da OPM relataram que não tiveram acesso a estudos sobre a história da matemática em sua formação, e assim foi possível apenas iniciar este estudo, sendo que os professores tiveram então acesso a livros de História da matemática como Boyer (1996), Eves (1995) e a busca em sites da internet.

A expectativa era de que nesse movimento de estudo do movimento histórico e lógico dos conceitos de razões trigonométricas se pudesse revelar a essência do conceito e seus nexos conceituais. Compreender esta essência possibilita pensar "teoricamente" e se aprofundar em relação ao conceito estudado, tornando-o elemento apropriado e instrumento para compreender a realidade (DAVYDOV, 1982).

Assim, os professores estudaram coletivamente textos históricos e tiveram condições de discutir o que seriam então conceitos e nexos conceituais imprescindíveis para apropriação dos estudantes em relação às razões trigonométricas. Reconheceram então que compreender quais são as razões trigonométricas (seno, cosseno e tangente) é importante, mas destacaram ainda que compreender que tais razões se alteram em função da inclinação, ou alteração do ângulo a ela relacionado é algo não destacado nas ações escolares.

Outra ação proposta na Oficina Pedagógica de Matemática, foi a definição de uma situação desencadeadora de aprendizagem do conceito escolhido (razões trigonométricas no triângulo retângulo).

A situação desencadeadora de aprendizagem deve contemplar a gênese do conceito, ou seja, a sua essência, ela deve explicitar a necessidade que levou a humanidade à construção do referido conceito, como foram aparecendo os problemas e as necessidades humanas em determinada atividade e como os homens foram elaborando as soluções ou sínteses no seu movimento lógicohistórico. (MOURA et al., 2010, p.103-104).

Como elemento da Atividade Orientadora de Ensino, a situação desencadeadora de aprendizagem pode ser apresentada como história virtual do 
conceito, jogo ou situação do cotidiano. No movimento de estudo teórico dentro da OPM os professores leram e discutiram sobre o conceito de situação desencadeadora de aprendizagem e então o objetivo consciente desta ação passou a ser reconhecer o que poderia ser considerado para os estudantes uma situação desencadeadora de aprendizagem para a compreensão dos nexos conceituais envolvidos em razões trigonométricas no triângulo retângulo.

Os professores em geral já possuem um repertório de situações para desenvolver com os estudantes o conceito de razões trigonométricas, entretanto elas estão vinculadas aos livros didáticos ou práticas que não são consideradas ‘inovadoras'. Não é característica principal da situação desencadeadora de aprendizagem que seja inovadora, o principal é como se organiza o ensino a partir dela, que questões são feitas, que formas de pensamento são potencializadas etc.

Durante a discussão coletiva para encontrar uma situação desencadeadora de aprendizagem os professores encontraram possibilidades relacionada à medida das pirâmides, ou medida de sombras de objetos entre outras, mas não as consideravam realmente como desencadeadoras da necessidade dos estudantes de se apropriar dos conceitos. Em determinado momento lembraram que boa parte dos estudantes lidavam com skate e de forma unânime reconhecendo então que o skate se apresentava como situação do cotidiano definiram que as demais ações de ensino seriam desencadeadas a partir do trabalho tendo a montagem de uma pista de skate como situação desencadeadora de aprendizagem. Esta se constituiu então como ponto de partida para o movimento coletivo dos professores de planejamento. A partir deste momento as demais ações e operações dos professores foram se definindo coletivamente. Os professores estudaram sobre a construção de uma pista a partir de sites e textos específicos (HIROSHI, 2007), bem como outros materiais didáticos e artigos de revista, identificaram a existência de poucos artigos sobre o tema vinculados às ações escolares.

Conforme tratavam do conteúdo e das ações, os professores foram orientados também a relacionar com a teoria e se reconhecer em atividade, reconhecer suas ações de planejamento, reconhecer suas ações de busca e de organização de material, de avaliação etc. 
É interessante observar que esse tipo de situação exige maior planejamento do professor e preparação, sendo fundamental a organização do ensino. Muitos detalhes devem ser previstos e organizados antecipadamente. Os professores entenderam que não seria o caso de apenas medir pistas de skate, mas construir uma pista de skate de dedo e resolveram então se desafiar a criar a própria pista de skate. Essa ação gerou um certo desconforto no grupo que entendeu que seria uma tarefa operacionalmente fácil e que sendo professores com domínio do conteúdo logo conseguiriam fazer. Ficaram então surpresos por levar uma tarde inteira para montar sua própria pista, e ter dificuldades em usar conceitos matemáticos essenciais que envolviam não só as razões trigonométricas, mas planificação, medidas, ângulos.

Figura 1 - Foto da rampa de skate de dedo construído pelos professores.

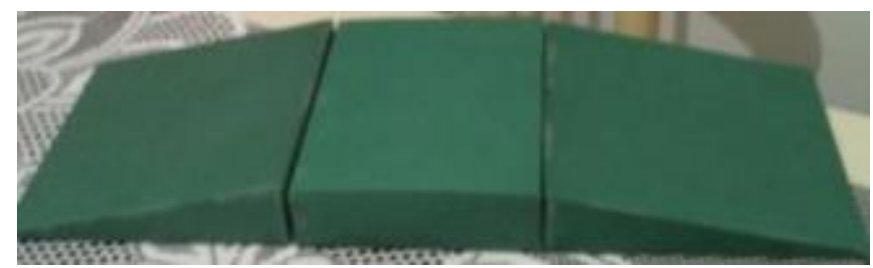

Fonte: Dados da pesquisa, 2015.

A todo momento os professores eram requisitados a relacionar os conceitos e elementos da atividade, bem como os conceitos e elementos da Atividade Orientadora de Ensino, conforme proposto por Moura (2001)

A atividade orientadora de ensino tem uma necessidade: ensinar; tem ações: define modo ou procedimentos de como colocar os conhecimentos em jogo no espaço educativo; e elege instrumentos auxiliares de ensino: os recursos metodológicos adequados a cada objetivo e ação (livro, giz, computador, ábaco, etc.). E, por fim, os processos de análise e síntese, ao longo da atividade, são momentos de avaliação permanente para quem ensina e aprende. (MOURA, 2001, p.155).

A necessidade do professor, se evidencia ao ensinar o conhecimento científico, nesse caso as relações trigonométricas (seno, cosseno, tangente) no triângulo retângulo. Também se reconhece o motivo e a necessidade dos alunos em apropriar-se do conceito de razões trigonométricas, por meio do problema desencadeador no caso a construção de uma pista de skate de dedo. 
De forma sintética, as ações associadas aos objetivos do projeto foram: aprofundamento do estudo histórico e lógico das relações trigonométricas em um triângulo retângulo; estudo dos conceitos envolvidos na montagem e uso da rampa de skate de dedo; planejamento e montagem da rampa; organização de ações para os estudantes que permitissem a apropriação de conceito das relações trigonométricas em um triângulo retângulo entre outras.

As operações associadas às ações anteriormente citadas foram: pesquisa em sites da internet e livros sobre o movimento histórico e lógico do conceito de relações trigonométricas em um triângulo retângulo; estudo de conceitos matemáticos; identificação de material apropriado para elaboração da rampa; elaboração de material de apoio para os estudantes entre outras.

Conforme as ações e operações iam se desenvolvendo o grupo de professores também realizava análises e reflexões sobre os resultados obtidos. Os professores também entenderam como relevante elaborar uma lista de exercícios e questões para a avaliação dos estudantes.

As ações planejadas coletivamente durante o primeiro semestre foram desenvolvidas com os estudantes no segundo semestre de 2015 nas aulas de dois professores participantes. Foi um momento de adequação das ações planejadas à realidade escolar. Inicialmente foram planejadas cinco aulas com uma turma do $1^{\circ}$. Ano do ensino Médio, entretanto toda a situação foi desenvolvida durante um mês em aulas de Matemática e Física em um total de 17 aulas. Algumas das condições que estenderam o tempo necessário para o desenvolvimento da atividade foram a redução de cinco minutos em cada aula devido ao período de greve, o acréscimo da sexta aula no dia escolar, o tempo de deslocamento de alunos para sala de informática onde foi possível exibir o vídeo escolhido e usar a lousa digital, e também outros assuntos relacionados a rotina escolar (chamada, acomodação dos alunos, ordem na sala).

As aulas foram gravadas em vídeo com autorização dos responsáveis. Segue uma descrição breve das ações e operações planejadas e desenvolvidas com os estudantes, bem como alguns resultados. 


\section{Ações e operações com os estudantes}

A primeira ação de ensino foi a exibição de um vídeo "Documentário sobre a prática do skate em Curitiba”. O objetivo desta ação foi a de aproximar os estudantes em relação a este esporte como tema de estudo. Boa parte dos estudantes tem esse tema como parte da realidade. Também foi possibilitado aos estudantes que relatassem suas experiências com o skate através de perguntas como: Qual a relação de vocês com o skate? Gostam? Se interessam? Usam como transporte? Existe uma relação do skate com a matemática? O que a matemática pode contribuir para a prática desse esporte? Os estudantes comentaram sobre a falta de pistas no bairro, as condições precárias e o excesso de frequentadores. Eles também discutiram em grupo, e apesar de 'ver' conceitos matemáticos não entendem que a matemática contribui para a prática do esporte, conforme figura 2.

Figura 2 - Relatório de um aluno.

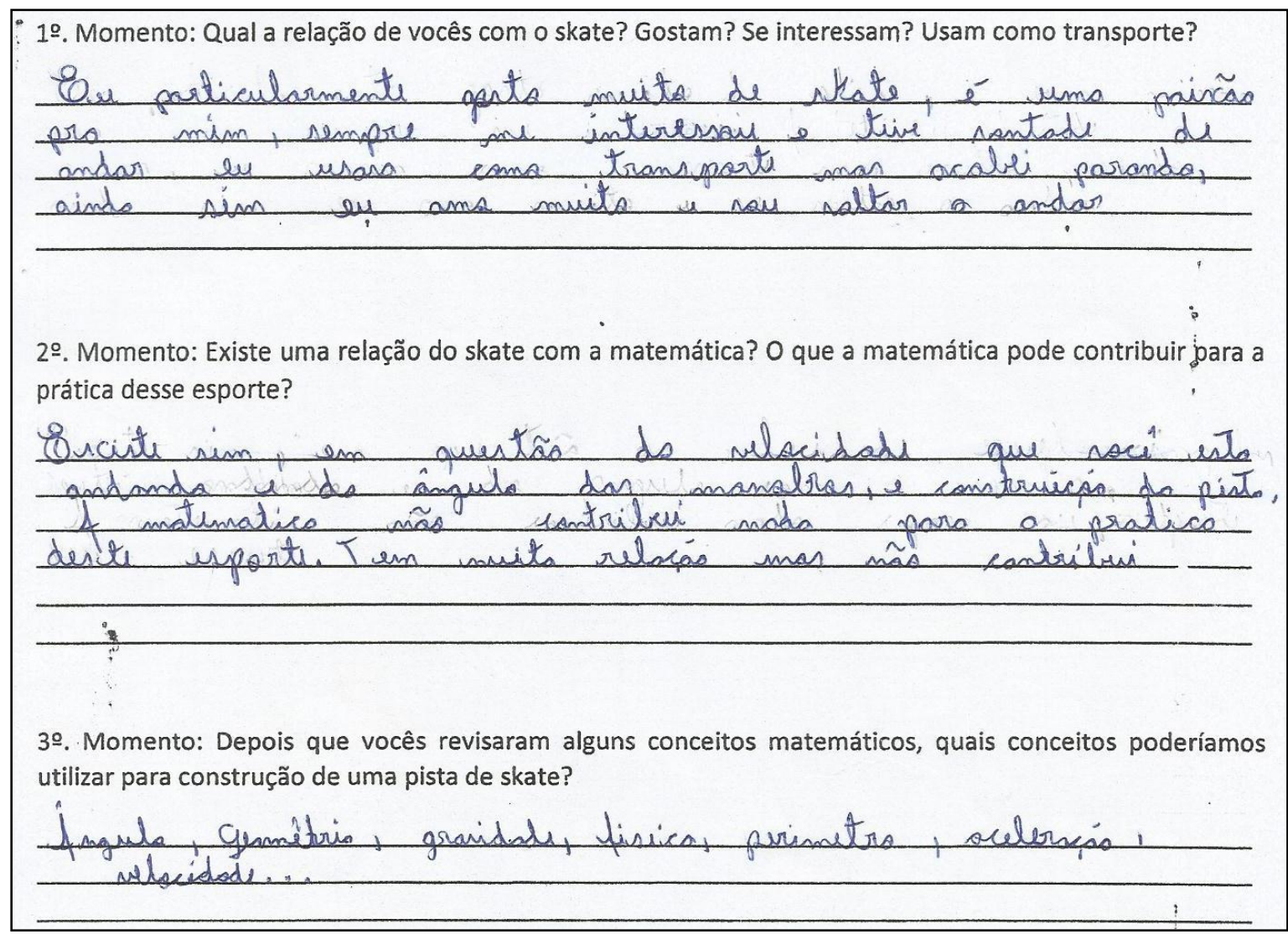

Fonte: Dados da pesquisa, 2015. 
Dentre as ações de ensino tornou-se possível trabalhar com conceitos de forma interdisciplinar. Considerando que no grupo haviam professores de matemática e física da mesma escola foi possível que a mesma turma explorasse também os conceitos de física envolvidos na prática do esporte, como impulso, velocidade da execução das manobras, cálculo do plano inclinado, etc.

Os recursos tecnológicos também foram explorados pelos professores. A escola possui lousa digital e algumas das relações e conceitos matemáticos com a pista de skate foram evidenciados através deste recurso, principalmente o que se referia a formas geométricas, ângulos de inclinação da pista, medidas de altura, perímetro, área etc.

Foi solicitado aos estudantes que também projetassem e montassem a sua própria pista de skate, conforme indicado na figura 3, a seguir.

Figura 3 - Relatório de um aluno.

2. Descreva suas ideias para montagem da pista. É importante lembrar que nesse momento o objetivo final não é montar a pista, mas ' projetar'. O projeto deve conter textos explicativos (sobre as ações que serão executadas) e desenhos/imagens/fotos que explicitem medidas da pista.

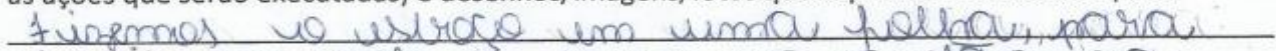

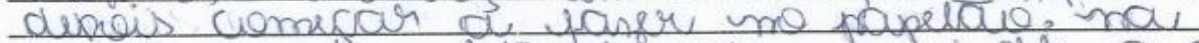

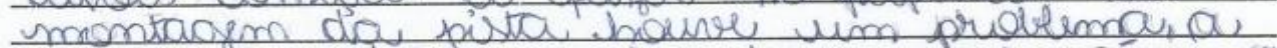

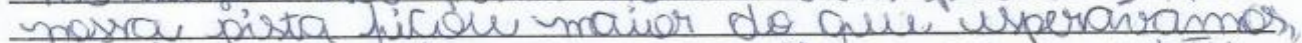

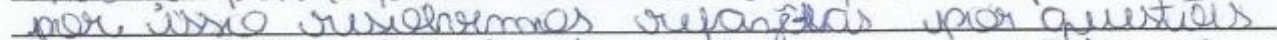
de estética. puacis de relanermas, percelumas

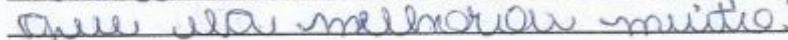

Fonte: Dados da pesquisa, 2015.

Os professores identificaram grupos com facilidade para construir a pista e com conhecimentos prévios de planificação (Figura 4) e também encontraram grupos com dificuldade na montagem de sólidos geométricos. 
Figura 4 - Planificação elaborada por estudantes de uma rampa de skate de dedo.

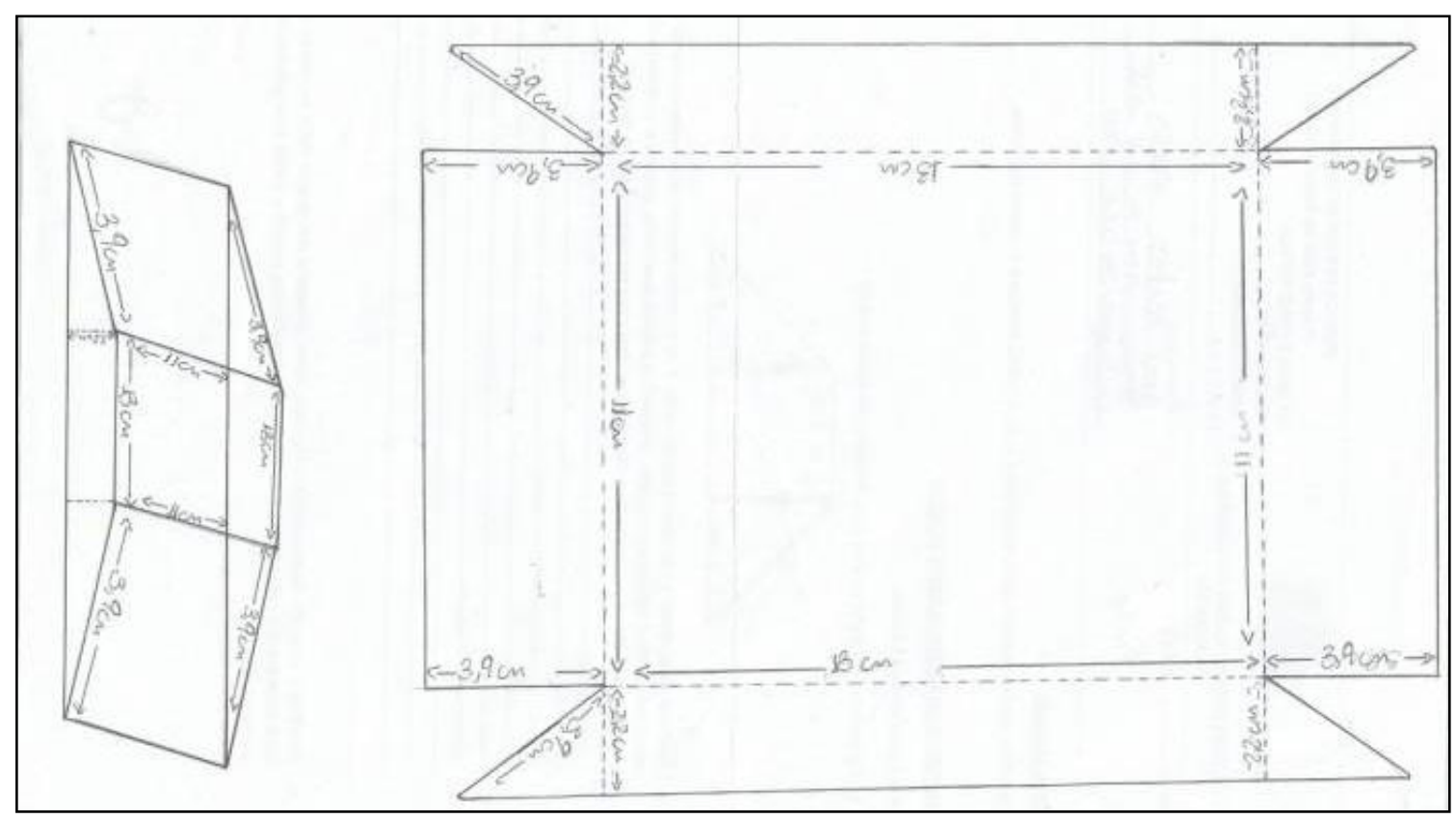

Fonte: Dados da pesquisa, 2015.

O objetivo nesta ação de projetar e montar uma pista de skate sem orientações específicas foi o de colocar aos estudantes o reconhecimento de conceitos matemáticos necessários para essa elaboração. Seguem algumas das pistas montadas pelos estudantes (Figura 5). 
Figura 5 - Pistas de skate de dedo montadas pelos estudantes.

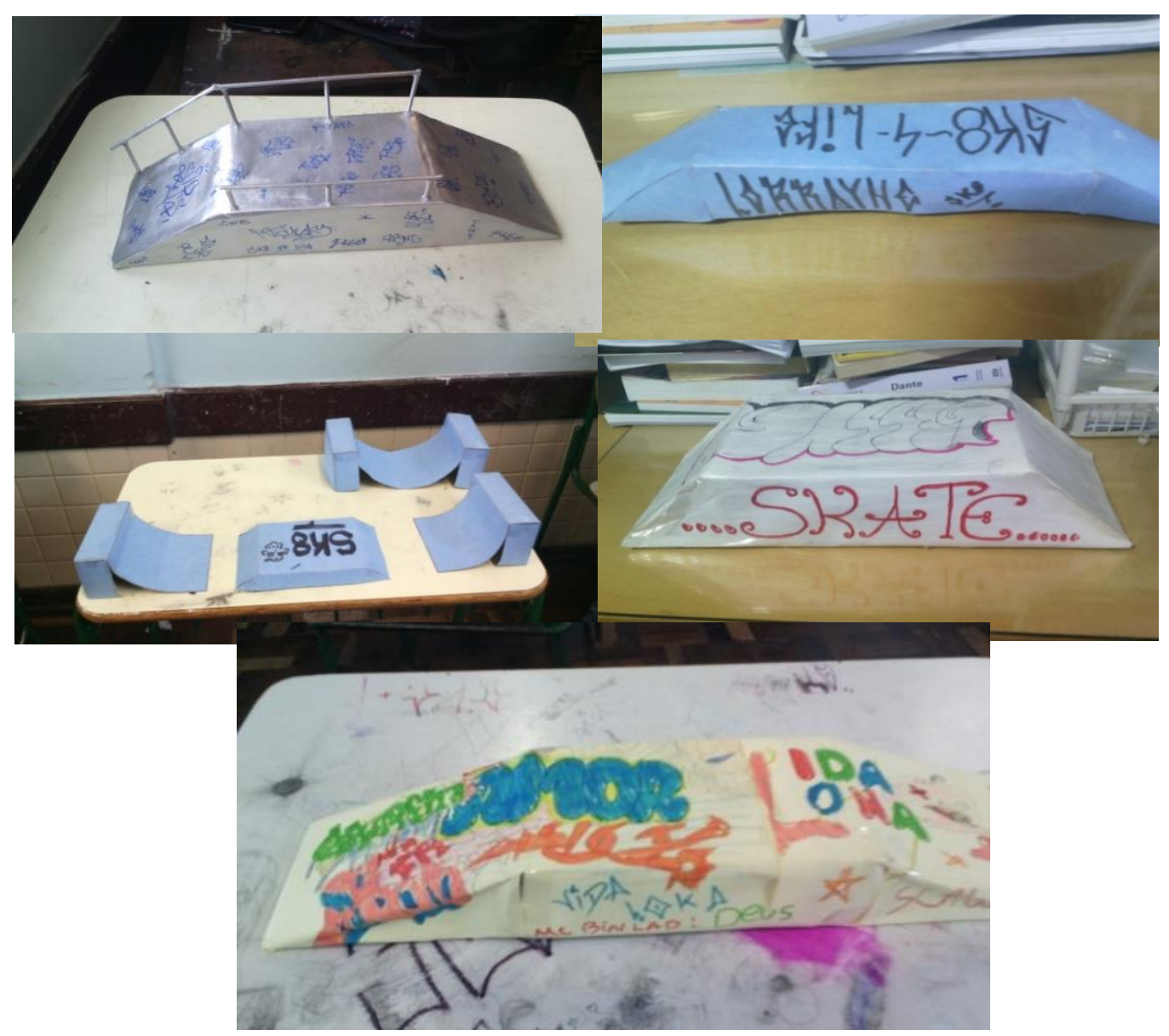

Fonte: Dados da pesquisa, 2015.

Posteriormente foi apresentado aos estudantes o desenho de uma rampa de skate com as medidas reais, para que fossem transformadas na escala 1:10. Sendo solicitado que registrassem as medidas de sua própria pista e comparassem. Estas pistas têm a mesma inclinação? Como podemos fazer para descobrir a inclinação de cada pista? Os alunos não encontraram dificuldades para responder a primeira pergunta, mas não recorreram às razões trigonométricas para identificar a inclinação da pista (Figura 6). 
Figura 6 - Resposta de um estudante.

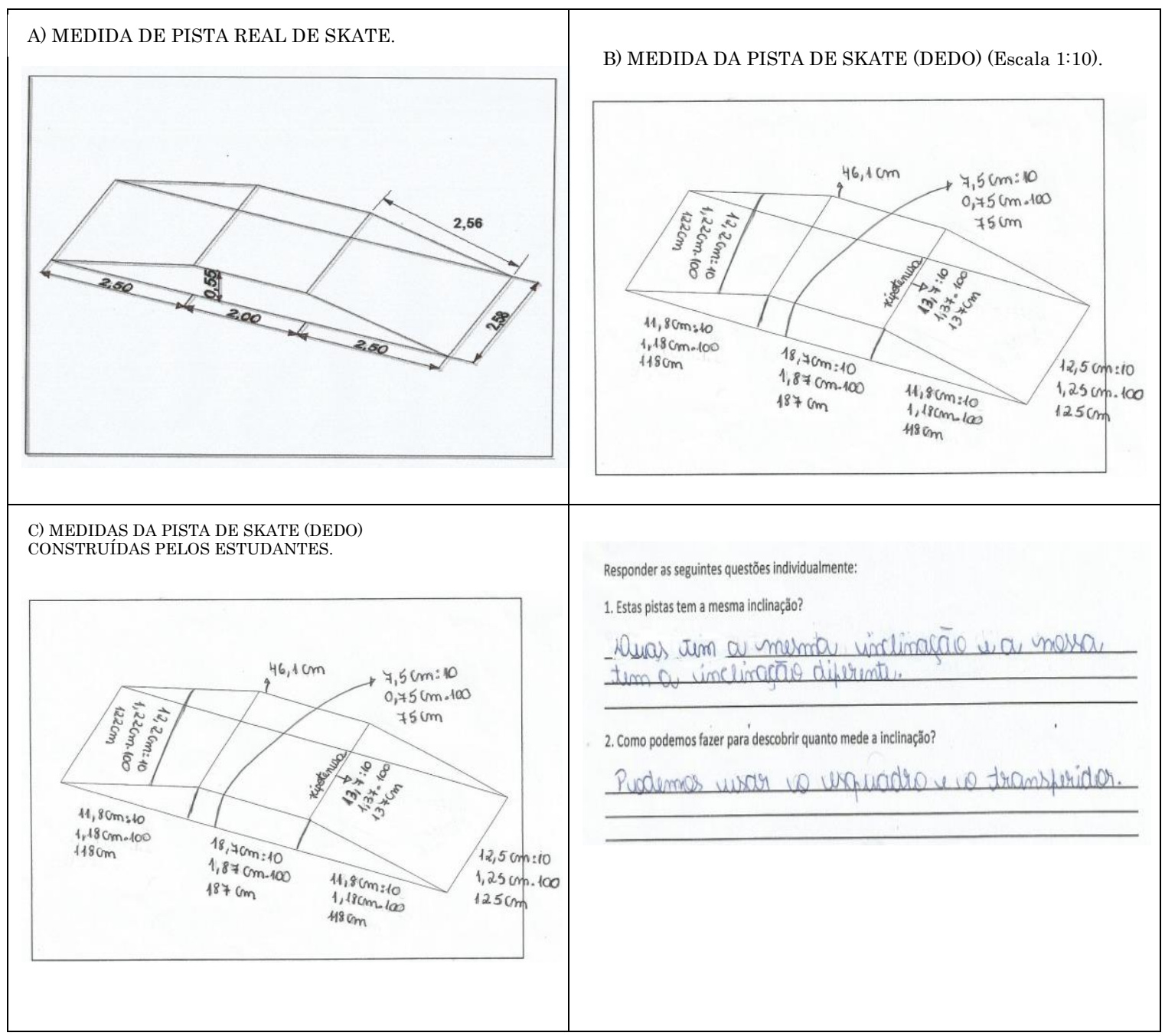

Fonte: Dados da pesquisa, 2015.

Para gerar nos estudantes a necessidade do conceito de razões trigonométricas foram discutidos em aula conceitos básicos como: ângulo reto, cateto oposto ao ângulo; cateto adjacente ao ângulo; hipotenusa, e escala. Foi solicitado aos estudantes que preenchessem uma tabela com as medidas de três pistas, representadas na figura 6: as medidas da pista real (A), as medidas da pista em escala 1:10 (B) e as medidas da pista que eles próprios confeccionaram (C). 
Os alunos não apresentaram dificuldades em preenchê-la, bem como, identificar os ângulos por meio da tabela de razões trigonométricas, conforme exposto na Figura 7.

Figura 7 - Preenchimento da tabela por um estudante.

\begin{tabular}{|c|c|c|c|}
\hline$=$ & FIGURAA & FIGURA B & FIGURAC \\
\hline $\begin{array}{c}\text { Cateto oposto/ cateto } \\
\text { adjacente }\end{array}$ & $\frac{0,55}{2,50}=0,22=\alpha \cong 12^{\circ}$ & $\frac{0,055}{0,25}=0,22=d \approx 12^{\circ}$ & $\frac{0,75}{1,18}=0,635 \approx d \cong 32^{\circ}$ \\
\hline $\begin{array}{c}\text { Cateto oposto/ } \\
\text { hipotenusa }\end{array}$ & $\frac{0,55}{2,56}=0,214=\alpha \cong 12^{\circ}$ & $\frac{0,055}{0,256}=0,214=\alpha \cong 12^{\circ}$ & $\frac{0,75}{1,37}=0,547=d=33^{\circ}$ \\
\hline $\begin{array}{c}\text { Cateto adjacentel } \\
\text { hipotenusa }\end{array}$ & $\frac{2,50}{2,56}=0,976=\alpha \cong 13^{\circ}$ & $\frac{0,25}{0,256}=0,976=d \cong 13^{\circ}$ & $\frac{1,18}{1,3 t}=0,861=d \cong 31^{\circ}$ \\
\hline
\end{tabular}

Fonte: Dados da pesquisa, 2015.

A ação seguinte proposta aos estudantes foi a de registrar possíveis medidas para os lados de um triângulo retângulo, dado que um dos ângulos era $12^{\circ}$. O objetivo desta ação era o de que os alunos compreendessem que poderiam identificar esta inclinação usando as medidas dos lados. Também foram indicadas ações para que os estudantes resolvessem exercícios variados sobre razões trigonométricas e avaliações escritas.

Em relação às dificuldades vivenciadas pelos professores podemos citar as seguintes: a falta da apropriação de conceitos prévios de matemática pelos estudantes, que atrasou a execução do projeto e, com isso, a aplicação das atividades acabou ficando cansativa para os alunos. Outra dificuldade foi a instalação de equipamentos (computador, projetor, lousa digital) durante as primeiras aulas, ainda que tenha sido realizada com antecedência. A redução do tempo das aulas de 50 minutos que passaram a ser de 45 minutos devido à greve dos professores, além de outros assuntos relacionados à rotina escolar (chamada, acomodação dos alunos, ordem na sala). 


\section{Considerações finais}

Neste texto pretendeu-se evidenciar os princípios que regem a organização da Oficina Pedagógica de Matemática como ação de extensão universitária estruturada como atividade, destacando necessidades dos professores, objeto e objetivos das ações. Considera-se como papel da universidade a organização de ações que promovam a formação continuada dos professores. Ainda que com caráter pontual de atuação, destaca-se o potencial da OPM para o trabalho com sistemas municipais e estaduais de ensino, pois da forma como é estruturada possibilita a formação do professor articulando teoria e prática.

Foi apresentada também neste texto a experiência de um ano da OPM/Curitiba com a participação de professores dos anos finais do ensino fundamental e do ensino médio, mas destaca-se que este modo de organização permite o trabalho com os professores de qualquer nível de ensino.

As análises realizadas sobre os encontros da OPM/Curitiba revelaram o movimento na atividade de ensino dos professores à medida em que o motivo dos professores e as ações dos professores também foram sendo transformadas. Cada professor assimilou novos sentidos à organização das ações que permitiram a objetivação de sua necessidade de ensinar e de assegurar condições de aprendizagem para seus estudantes. Desta forma, nesse processo de formação, os professores viram a necessidade de reorganizar suas ações e o fizeram por meio de apropriações de forma coletiva de realização da atividade de ensino. Os professores participantes obtiveram avanços na sua organização de trabalho, dando sentido a sua prática e metodologia de ensino. A AOE foi uma novidade aos professores que desconheciam tal movimento teórico e de organização de ensino.

As dificuldades surgiram na mudança dessa organização, saindo do método tradicional para o ensino como atividade. O planejamento das aulas, a clareza quanto à intencionalidade e a definição de instrumentos adequados para alcançar os objetivos, assegurando flexibilidade suficiente para permitir mudanças de rumos conforme as necessidades surgiram na interação com os alunos e o objeto de aprendizagem. Destaca-se que a AOE possibilita que o docente se desenvolva 
profissionalmente, implicando na capacidade de pensar teoricamente as situações de ensino, conscientizar-se de suas ações, o que tornam as aulas mais significativas para os alunos.

A situação desencadeadora de aprendizagem escolhida pelo grupo, também foi responsável pelo sucesso do projeto. A rampa de skate de dedo fez com que os alunos se interessassem e se apropriassem do conceito de razões trigonométricas no triângulo retângulo. Os resultados dos exercícios demonstraram o progresso dos alunos nesse conhecimento científico, ao compreenderem os princípios gerais do conceito de relações trigonométricas no triângulo retângulo, tendo condições de lidar com as variações particulares, com poucas intervenções do professor.

Entende-se que a elaboração de ações de extensão de curto prazo é essencial no sentido de aproximar ou informar os participantes sobre determinado assunto, entretanto para a qualidade maior do processo de formação dos professores é importante pensar em ações continuadas em que o participante tenha condições de interagir com os colegas, receber informações, atuar em seu local de trabalho, trazer dúvidas, reavaliar etc. Dessa forma, o fato de ser estruturada como atividade supera o modelo 'fast' de cursos de ações prontas e rápidas que não promovem o acompanhamento dos professores após a realização da ação.

A OPM se caracteriza essencialmente por ser um espaço de aprendizagem e, no caso de Curitiba, ela se apresenta como uma ação de extensão voltada preferencialmente para a formação continuada de professores da rede pública, entretanto é importante destacar que como espaço de aprendizagem ela pode agregar alunos da licenciatura em formação inicial, participantes de projeto de iniciação científica (da graduação ou do ensino médio). Uma estudante da escola em que foi realizada a intervenção foi escolhida como bolsista de ensino médio e acompanhou o trabalho durante o segundo semestre de 2015, elaborando também um relatório referente e aprofundado sobre razões trigonométricas no triângulo retângulo.

$\mathrm{O}$ processo de pesquisa também se vincula à extensão realizada na OPM, que se apresenta também como espaço para estudo e investigação do processo 
formativo dos professores. Assim, mais do que extensão, a OPM estruturada como atividade se revela como espaço para articular o tripé ensino/pesquisa/extensão.

\section{Referências}

BOYER, C.B. História da matemática. 2.ed. São Paulo: Editora Edgard Blucher Ltda., 1996.

CEDRO, W. L. O espaço de aprendizagem e atividade de ensino: o clube de matemática. 2004, 157f. Dissertação (Mestrado em Educação: Ensino de Ciências e Matemática) - Universidade de São Paulo, São Paulo, 2004.

DAVIS, C.L.F.; NUNES, M. M.R; ALMEIDA, P.C.A.A. Formação continuada de professores: uma análise das modalidades e das práticas em estados e municípios brasileiros. Relatório Final. São Paulo: Fundação Carlos Chagas, Fundação Victor Civita, Junho, 2011.

DAVYDOV, V.V. Tipos de generalización em La enseñanza. Habana: Editorial Pueblo y Educación, 1982.

EVES, H. Introdução à história da matemática. Campinas, Ed. Unicamp, 1995.

HIROSHI, M. $1^{\text {a }}$ Pista de Skate Pública do Piauí. Revisa Cemporcento Skate, Piauí, jun. 2007. Disponível em: $<$ http://www.cemporcentoskate.com.br/fiksperto.php?id=3068 $>$ Acesso em: 09 jun. 2015.

LEONTIEV, A. N. O desenvolvimento do psiquismo. Lisboa: Horizonte Universitário, 1975.

Actividad, conciencia, personalidad. 2. ed. Havana: Pueblo y Educación, 1983.

Uma contribuição à teoria do desenvolvimento da psique infantil.

In:VIGOTSKI, L.S.;LURIA, A.R, LEONTIEV, A.N. Linguagem, desenvolvimento aprendizagem. Ícone Editora, 1994.

MORAES, S.P.G.; ARRAIS, L.F.L.; GOMES, T.S.; GRACILIANO, E.C. VIGNOTO, J. Pressupostos teórico-metodológicos para formação docente na perspectiva da teoria histórico-cultural. Revista Eletrônica de Educação, v. 6, n. 2, nov. 2012. Programa de Pós-Graduação em Educação, Universidade Federal de São Carlos, Brasil.

MORETTI, V. D.; MOURA, M.O. de. Professores de matemática em atividade de ensino: contribuições da perspectiva histórico-cultural para a formação docente. Ciência \& Educação, v.17, n.2, p.435-450, 2011. 
MOURA, M.O.de. A construção do signo numérico em situações de ensino. Doutorado em Educação. Faculdade de Educação, Universidade de São Paulo. 1992.

MOURA, M.O.de (coord). Controle da variação de quantidades: atividades de ensino. São Paulo, FEUSP, 1996.

MOURA, M. O. A atividade de ensino como ação formadora. In: CASTRO, A. D.; CARVALHO, A. M. P. (Orgs.). Ensinar a ensinar. São Paulo: Pioneira, 2001. P. 143-162.

2010.

A atividade pedagógica na teoria histórico cultural. Brasília: LiberLivro,

MOURA, M.O.de; SFORNI, M.; ARAÚJO, E. Objetivação e apropriação de conhecimentos na atividade orientadora de ensino. Teoria e Prática da Educação, v. 14, n. 1, p. 39-50, jan/abr. 2011.

SILVA, A. L.; PALLU, F.; PANOSSIAN, M. L.; SCHREINER, L.. Skate de dedo e as relações trigonométricas no triângulo retângulo. In: XII Encontro Nacional de Educação Matemática, 2016, São Paulo. Anais do $12^{\circ}$ Encontro Nacional de Educação Matemática, 2016.

SOUSA, M.C.; PANOSSIAN, M.L.; CEDRO, W. Do movimento lógico e histórico à organização do ensino: o percurso dos conceitos algébricos. 1. ed. Campinas: Mercado de Letras, 2014. 184p.

VIGOTSKI, L.S. A construção do pensamento e da linguagem. São Paulo, Brasil: Martins Fontes, 2001

VYGOTSKY. Obras escogidas. Tomo V. Madri: Visor, 1997.

Recebido em março de 2017. Aprovado em janeiro de 2018. 